\title{
Correlation between body mass index and waist circumference in Nigerian adults: implication as indicators of health status
}

\author{
Shalom Nwodo Chinedu, 1,2 Olubanke O. Ogunlana, ${ }^{1,2}$ Dominic E. Azuh,2,3 \\ Emeka E.J. Iweala, ${ }^{1,2}$ Israel S. Afolabi, ${ }^{1,2}$ Chidi C. Uhuegbu, 2,4 Mercy E. Idachaba, 2,5 \\ Victor C. Osamor ${ }^{2,6}$ \\ ${ }^{1}$ Department of Biological Sciences, ${ }^{2}$ Public Health and Well Being Research Group, ${ }^{3}$ Department \\ of Economics and Development Studies, ${ }^{4}$ Department of Physics, ${ }^{5}$ Covenant University Health \\ Center, ${ }^{6}$ Department of Computer and Information Sciences, Covenant University, Ota, Ogun \\ State, Nigera
}

Significance for public health

This manuscript describes the correlation between body mass index, waist circumference and body weight of two communities in Ota, Ogun State, Nigeria and the use of these anthropometric measures for body weight classification in human populations of the selected communities. This was carried out to evaluate the health status of the indigenes of the two communities for proper health awareness and public health intervention programmes.

\section{Abstract}

Background. Anthropometric measures have been widely used for body weight classification in humans. Waist circumference has been advanced as a useful parameter for measuring adiposity. This study evaluated the correlation between body mass index (BMI) and waist circumference and examined their significance as indicators of health status in adults.

Design and Methods. The subject included 489 healthy adults from Ota, Nigeria, aged between 20 and 75 years, grouped into early adulthood (20-39 years), middle adulthood (40-59 years) and advanced adulthood (60 years and above). Weight, height and abdominal circumference were measured. BMI was calculated as weight $\mathrm{kg} / \mathrm{height}^{2}$ $\left(\mathrm{m}^{2}\right)$ and World Health Organization cut-offs were used to categorize them into normal, underweight, overweight and obese.

Results. Abnormal weight categories accounted for $60 \%$ of the subjects (underweight $11 \%$, overweight $31 \%$, and obese 18\%). The waist circumference of overweight and obese categories were significantly $(\mathrm{P}<0.05)$ higher than the normal weight category. There was no significant difference between waist circumference of underweight and normal subjects. The correlation coefficient values of BMI with waist circumference $(\mathrm{r}=0.63)$, body weight $(\mathrm{r}=0.76)$ and height $(\mathrm{r}=-0.31)$ were significant $(\mathrm{P}<0.01)$ for the total subjects.

Conclusions. The study indicates that waist circumference can serve as a positive indicator of overweight and obesity in the selected communities; however, it may not be used to determine underweight in adults. Regular BMI and waist circumference screening is recommended as an easy and effective means of assessing body weight and in the prevention of weight related diseases in adults.

\section{Introduction}

Anthropometrics, the measurement of body parts, has been used at different age categories, as a sensitive indicator of wellness, maturation and development in humans. It is the single most universally applicable, inexpensive and non-invasive method available for the assessment of size, proportion and composition of human body. ${ }^{1,2}$ Height and weight are the two most easily obtained anthropometric measures and have been used extensively in screening and monitoring programs because abnormal weights categories (underweight, overweight and obesity) have been considered as risk factors for various diseases. ${ }^{3}$

Body mass index [BMI, weight $\mathrm{kg} / \mathrm{height}^{2}$ ] is presently the most often used and widely satisfactory methods of distribution of body weight and classification of medical risk. ${ }^{4}$ BMI is a useful determinant of adiposity in early and middle-aged adults. ${ }^{5}$ However, an important restriction of BMI is its inability to recognize between fat mass and fatfree mass, which is a good indicator of health status. ${ }^{6}$ In addition, the robustness of BMI as an indicator of fatness in advanced adulthood is limited. ${ }^{7}$ This is because the fat-free mass reduces with aging, without a change in overall weight. ${ }^{8}$ In contrast, waist circumference represents a measure of adiposity that takes into account the assemblage of abdominal fat. ${ }^{4}$ It is easy to measure and interpret.

Obesity has been defined as an abnormal accumulation of fat in the adipose tissue throughout the body. ${ }^{9}$ It is the most common nutritional disorder in humans from wealthy societies. It is a medical condition in which excess fat has been accumulated to an extent that it may have an adverse effect on health. ${ }^{9}$ Overweight is defined as body weight that exceeds the acceptable weight for a particular person and it is based on the individual's age, height and/or frame size. ${ }^{10}$ Overweight is determined by BMI value of $25-29.9 \mathrm{~kg} / \mathrm{m}^{2}$ while obesity is defined by BMI value of greater than or equal to $30 \mathrm{Kg} / \mathrm{m}^{2} .^{9}$ Excess body weight categories have been associated with physical discomfort, psychological trauma and disposes the individual to a complex health condition termed metabolic syndrome characterized by diabetes, lipid disorders, sleep apnea, certain type of cancer, osteoarthritis and hypertension leading to accelerated aging and cardiovascular diseases. ${ }^{11-15}$ Certain types of medications, lack of physical exercise, excessive intake of dietary calories, genetic susceptibility and endocrine disorders are some of the commonly causes of obesity. ${ }^{16}$ Obesity has reached epidemic levels not only in developed nations but also in developing nations. ${ }^{11}$ The marked increase in the prevalence of obesity has been 
ascribed to an exposure to a toxic environment which implicitly discourages physical activity and explicitly encourages excessive intake of dietary calories. ${ }^{16}$ Genetic susceptibility, endocrine disorders and certain types of medications are also causes of obesity.

Underweight, on the other hand, is defined as lack of sufficient body weight; it is usually associated with deficient nutritional reserves in the body and high risk of mortality in times of ill-health. ${ }^{17}$

There is paucity of information on the anthropometric data for predicting the health status of the middle aged and advanced aged adults especially from Africa. ${ }^{18}$ This study examined the trend in body mass index (BMI) of different adult age groups: 20 to 39 years (early adulthood); 40 to 59 years (middle adulthood) and 60 years and above (advanced or late adulthood) and the association between BMI and waist circumference amongst the adults in Ota, Nigeria.

\section{Design and Methods}

The study was carried out between April to May, 2012 at Iyesi and Ilogbo communities in Ota, Ado-Odo/Ota Local Government of Ogun State, Nigeria. Approvals were obtained from Covenant University Ethical Committee and the Local Government Authorities. A total of 489 healthy subjects, aged between 20 and 75 years participated in the study. None of the female subjects was pregnant at the period of the study. The age, sex, height (m), weight (kg) and waist circumference (cm) of the subjects were recorded after obtaining their consent. Weight was measured to the nearest $0.01 \mathrm{kKg}$ using Produex ${ }^{\mathrm{TM}}$ digital balance, Springfield, USA. Height was measured to the nearest $0.001 \mathrm{~m}$ using meter rule with the subject standing upright, barefooted, without a cap or headgear. Waist circumference was measured to the nearest $0.5 \mathrm{~cm}$, at the level of the umbilicus and the superior iliac crest using a normal tailoring tape. The measurement was made with the subject standing upright, feet together and arms hanging freely at the sides. BMI was calculated as weight $(\mathrm{kg}) / h^{2}$ eight ${ }^{2}\left(\mathrm{~m}^{2}\right)$. Body weight categories were defined according to WHO BMI cut-offs as follows: underweight as $18.4 \mathrm{~kg} / \mathrm{m}^{2}$ or below; normal weight as $18.5-24.9 \mathrm{~kg} / \mathrm{m}^{2}$; overweight as $25.0-29.9 \mathrm{~kg} / \mathrm{m}^{2}$, and obese as BMI of $30.0 \mathrm{~kg} / \mathrm{m}^{2}$ or greater. ${ }^{9}$

\section{Statistical analysis}

All data were coded and entered into the SPSS (Statistics Package for Social Science) version 13.0. The categorical variables were presented as averages and percentages. The differences in mean values of height, weight, BMI and waist circumference among different age categories and between sexes were examined by ANOVA analysis. Statistical significance was set at $95 \%$ confidence interval.

\section{Results}

Out of a total of the 489 subjects, 301 were in early adulthood, 151 in middle adulthood and 37 in advanced adulthood categories. Figure 1 shows the percentage distribution of the body weights of the subjects. Sixty percent (60\%) were in the abnormal weight (underweight, overweight and obesity) categories while $40 \%$ were in the normal weight category. Table 1 shows the anthropometric value for the subjects. In the three age groups, the mean BMI values were significantly $(\mathrm{P}<0.05)$ lower in underweight and significantly $(\mathrm{P}<0.05)$ higher in overweight and obesity weight categories compared to the normal weight. The mean BMI values were significantly $(\mathrm{P}<0.05)$ higher in obese male compared to obese female in early adulthood and significantly higher in obese female compared to obese male in middle adulthood (Table 2).
In advanced adulthood, however, the mean BMI value of obese male was not significantly different from obese female.

Table 2 compares the mean BMI and waist circumference values in early, middle and advanced adulthood categories of subjects. The mean waist circumference values in obese and overweight male and female were significantly higher than that of normal weight subjects in all the age categories. While unlike the BMI values, the mean waist circumference values of underweight male and female were not significantly different from normal weight subjects (Table 2).

Figure 2 displays the frequency in percentages of the BMI distributions in the different age categories. The prevalence of normal weight subjects was observed in early and advanced adulthood while over-
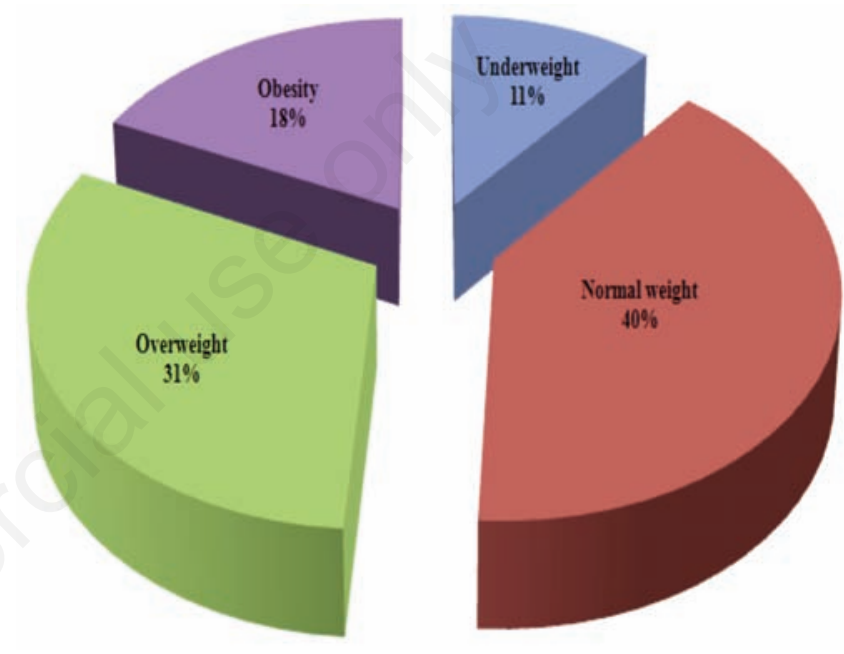

Figure 1. Percentage distributions of the Body weight categories of the study population based on $\mathrm{BMI}$; abnormal weight, $60 \%$ (underweight, 11\%; overweight, $31 \%$; obesity, 18\%), normal weight $40 \%$.

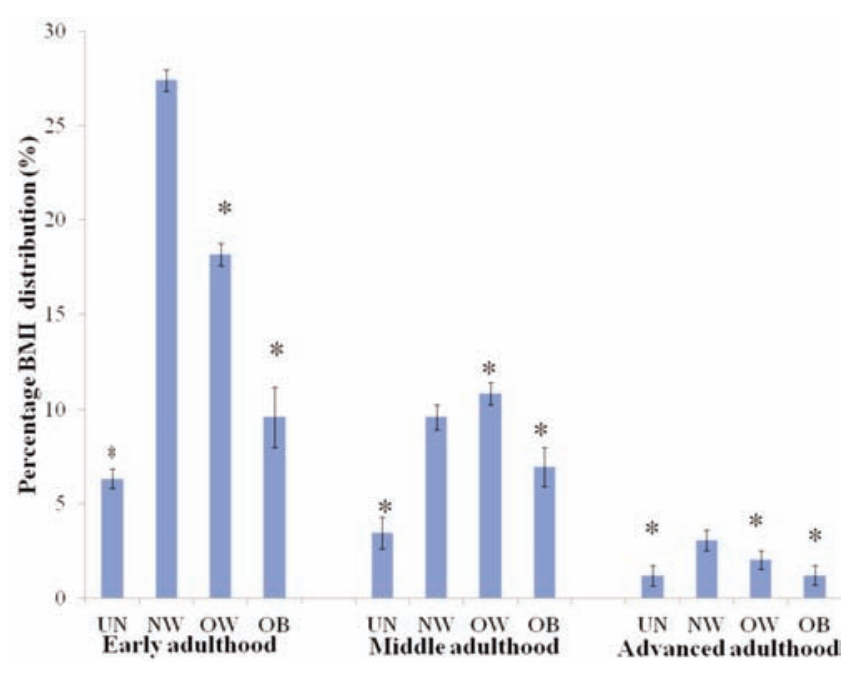

Figure 2. Percentage distribution of body weight categories in early-, middle- and advanced - adulthood. Values are expressed as mean \pm standard error of mean. UN = underweight, $\mathrm{NW}=$ normal weight, $\mathrm{OW}=$ overweight, and $\mathrm{OB}=$ obese. 
weight was prevalent in middle adulthood. Figure 3 displays the waist circumference measurement in different BMI distribution categories. There was no significant difference between the waist circumference measurement in underweight and normal weight BMI categories. However, there was significant $(\mathrm{P}<0.05)$ increases in the waist circumference of overweight and obesity BMI categories compared to normal weight BMI category. In addition, the waist circumference of overweight male was significantly $(\mathrm{P}<0.05)$ higher than that of overweight female.

Table 3 shows the correlation of BMI, waist circumference, body weight and height. There was significant $(\mathrm{P}<0.01)$ positive correlation values between $\mathrm{BMI}$, waist circumference and body weight, and negative correlation values between BMI and height in both male and female subjects (Table 3 ). The correlation of BMI with waist circumference $(r=0.75)$ and body weight $(r=0.85)$ is more positive and stronger in female than in male $(\mathrm{r}=+0.55$ and +0.77 respective) subjects. In addition, for both sex category, the correlation of BMI with body weight $(\mathrm{r}=0.76)$ is more than the correlation of BMI with waist circumference $(\mathrm{r}=0.63)$.

\section{Discussion}

This study evaluates the correlation between BMI and waist circumference amongst adult populations in two rural communities in Ota, Nigeria. The study shows the prevalence of abnormal weight categories among the adults of different age categories and an association between body weights, BMI and waist circumference in the two communities. Although there are several reports on weight abnormality patterns among Nigerian adults, ${ }^{11,18}$ none, to the best of our knowledge, associated BMI and waist circumference in Nigerian adult populations.
The findings in the study indicated that majority of subjects in the early adulthood (20-39 years) category have normal weight (Table 1 and Figure 2). This is consistent with the reports of other researchers in Lebanon and Nigeria which indicated that most University students (early adults) have normal weight. ${ }^{11,19}$ The prevalence of normal weight in this age category was more in female (50\%) than the male (44.2\%). This might be due to the consciousness of the female to the societal perception which encourages slender shaped females. ${ }^{11}$ The high prevalence of overweight in this age category (Table 1; Figure 2) has also been reported among young adults..$^{20-22}$ The relative prevalence of overweight and obesity in abnormal weight subjects might be due to unhealthy eating habits highly associated with this age group. ${ }^{23}$ Overweight in young adults may have deleterious effects on their subsequent self-esteem, social and economic characteristics and physical health. ${ }^{24}$ It is therefore necessary to monitor body weight regularly in order to reduce abnormal weight and its attendant related diseases.

The information on the body composition and changes associated with advanced adulthood is imperative for proper evaluation of their functional health status. Overweight was prevalent in both the male (30.8\%) and female (30.0\%) subjects in the advanced adulthood category (Table 1). The observed prevalence of overweight subjects in this age group is corroborated by the report of Houston et al. ${ }^{25}$ who reported that the prevalence of overweight in older adults is as a result of mobility limitation associated with the age group.

The highest prevalence of overweight was recorded at the middle adulthood; it was $41.3 \%$ and $38.4 \%$ respectively for the male and female subjects (Table 1). The high incidence of overweight in this age group has been attributed to bad eating habit (diet rich in lipids and carbohydrates) and eating pattern (indulgence in late heavy night meal), substitution of home prepared meal with fast and pre-prepared processed foods, lack of exercise and strenuous work habit or additional work hours. ${ }^{26}$ Regular physical activity, good eating habits and high intake of

Table 1. Anthropometric value for early-, middle- and advanced adulthood.

\begin{tabular}{|c|c|c|c|c|c|c|}
\hline Age group & Body weight category & Sex & $\begin{array}{l}\text { Mean height } \\
\text { (m) }\end{array}$ & $\begin{array}{c}\text { Mean weight } \\
\text { (kg) }\end{array}$ & $\begin{array}{c}\text { Mean BMI } \\
\left(\mathrm{kg} / \mathrm{m}^{2}\right)\end{array}$ & $\begin{array}{l}\text { BMI distribution } \\
\text { within gender (\%) }\end{array}$ \\
\hline Early adulthood (20-39 years) & $\begin{array}{l}\text { Underweight } \\
\text { Normal weight } \\
\text { Overweight } \\
\text { Obese }\end{array}$ & $\begin{array}{l}\mathrm{M} \\
\mathrm{F} \\
\mathrm{M} \\
\mathrm{F} \\
\mathrm{M} \\
\mathrm{F} \\
\mathrm{M} \\
\mathrm{F}\end{array}$ & $\begin{array}{l}1.64 \pm 0.09 \\
1.65 \pm 0.02 \\
1.69 \pm 0.02 \\
1.62 \pm 0.01 \\
1.65 \pm 0.02 \\
1.60 \pm 0.01 \\
1.50 \pm 0.13 \\
1.62 \pm 0.01\end{array}$ & $\begin{array}{l}48.67 \pm 4.59 \\
46.96 \pm 1.23 \\
65.58 \pm 1.55 \\
56.50 \pm 0.54 \\
73.25 \pm 2.08 \\
68.07 \pm 0.77 \\
83.55 \pm 3.03 \\
89.70 \pm 1.78\end{array}$ & $\begin{array}{c}18.03 \pm 0.28^{*} \\
17.15 \pm 0.25^{*} \\
22.86 \pm 0.43 \\
21.48 \pm 0.14 \\
26.75 \pm 0.43^{*} \\
26.48 \pm 0.16^{*} \\
39.63 \pm 0.85^{* a} \\
34.34 \pm 0.54^{* a}\end{array}$ & $\begin{array}{c}10.8 \\
7.9 \\
44.2 \\
50.0 \\
28.5 \\
31.6 \\
16.5 \\
10.5\end{array}$ \\
\hline Middle adulthood (40-59 years) & $\begin{array}{l}\text { Underweight } \\
\text { Normal weight } \\
\text { Overweight } \\
\text { Obese }\end{array}$ & $\begin{array}{l}\text { M } \\
\text { F } \\
\text { M } \\
\text { F } \\
\text { M } \\
\text { F } \\
\text { M } \\
\text { F }\end{array}$ & $\begin{array}{c}1.82 \pm 0.01 \\
1.61 \pm 0.01 \\
1.75 \pm 0.02 \\
1.65 \pm 0.2 \\
1.73 \pm 0.01 \\
1.58 \pm 0.02 \\
1.63 \pm 0.03 \\
1.60 \pm 0.01\end{array}$ & $\begin{array}{l}50.32 \pm 2.47 \\
40.00 \pm 0.41 \\
67.98 \pm 2.91 \\
59.92 \pm 1.48 \\
80.56 \pm 1.47 \\
67.21 \pm 1.75 \\
84.18 \pm 2.99 \\
87.67 \pm 1.94\end{array}$ & $\begin{array}{c}15.39 \pm 0.62^{*} \\
15.50 \pm 0.20^{*} \\
21.93 \pm 0.37 \\
21.92 \pm 0.29 \\
26.99 \pm 0.26^{*} \\
26.94 \pm 0.32^{*} \\
31.53 \pm 0.22^{* a} \\
34.51 \pm 0.80^{*}\end{array}$ & \begin{tabular}{c|}
17.3 \\
1.4 \\
33.3 \\
30.1 \\
41.3 \\
38.4 \\
8.0 \\
30.1
\end{tabular} \\
\hline Advanced adulthood (60+ years) & $\begin{array}{l}\text { Underweight } \\
\text { Normal weight } \\
\text { Overweight } \\
\text { Obese }\end{array}$ & $\begin{array}{c}\text { M } \\
\text { F } \\
M \\
F \\
M \\
F \\
M \\
F\end{array}$ & $\begin{array}{l}1.79 \pm 0.05 \\
1.41 \pm 0.04 \\
1.77 \pm 0.04 \\
1.72 \pm 0.04 \\
1.63 \pm 0.04 \\
1.59 \pm 0.03 \\
1.71 \pm 0.01 \\
1.60 \pm 0.03\end{array}$ & $\begin{array}{l}55.00 \pm 2.89 \\
35.57 \pm 2.50 \\
68.58 \pm 6.23 \\
64.27 \pm 2.33 \\
72.28 \pm 5.01 \\
65.52 \pm 2.00 \\
94.03 \pm 2.02 \\
83.03 \pm 5.16\end{array}$ & $\begin{array}{c}16.60 \pm 0.38^{*} \\
17.58 \pm 0.46^{*} \\
21.78 \pm 0.96 \\
21.79 \pm 0.29 \\
27.03 \pm 0.84^{*} \\
25.83 \pm 0.27^{*} \\
32.34 \pm 0.63^{*} \\
32.48 \pm 0.89^{*}\end{array}$ & \begin{tabular}{c|}
7.7 \\
10.0 \\
38.5 \\
50.0 \\
30.8 \\
30.0 \\
21.3 \\
10.0
\end{tabular} \\
\hline
\end{tabular}

Values are expressed as mean \pm standard error of mean. *Values significantly $(\mathrm{P}<0.05)$ different from normal weight. aValues within the same BMI distribution, but significantly $(\mathrm{P}<0.05)$ different among gender. 
diet rich in fibre and non-starchy foods have been recommended as preventive factors against overweight and obesity in the middle age population.

The association of body mass index (BMI), body weight and waist circumference is reported in this study. There is significant $(\mathrm{P}<0.01)$ association between BMI, body weight and waist circumference (Table 3 ), however, this is not the case with BMI and height. The connection of BMI with body weight $(\mathrm{r}=0.76)$ is more positive than that of waist circumference $(r=0.63)$. Despite this, there is still relatively high association between BMI and waist circumference across both gender (Table 3). This report is supported by the report of Vazquez and others. ${ }^{27}$ The significant increases observed in the mean waist circumference of overweight and obesity BMI distribution further established the relationship of BMI and waist circumference (Table 2; Figure 3) with increase in weight. Ford and others support the use of waist circumference as a measurement of overweight and obesity in other to predict health risk in human subjects. ${ }^{28}$ It was argued that waist circumference has been shown to be a good or better predictor of metabolic syndrome than BMI. ${ }^{27}$ The high prevalence of obesity observed in this study, is considerably lower than the reported value from United States of America, but comparable to United kingdom, Germany and Australia. ${ }^{29}$

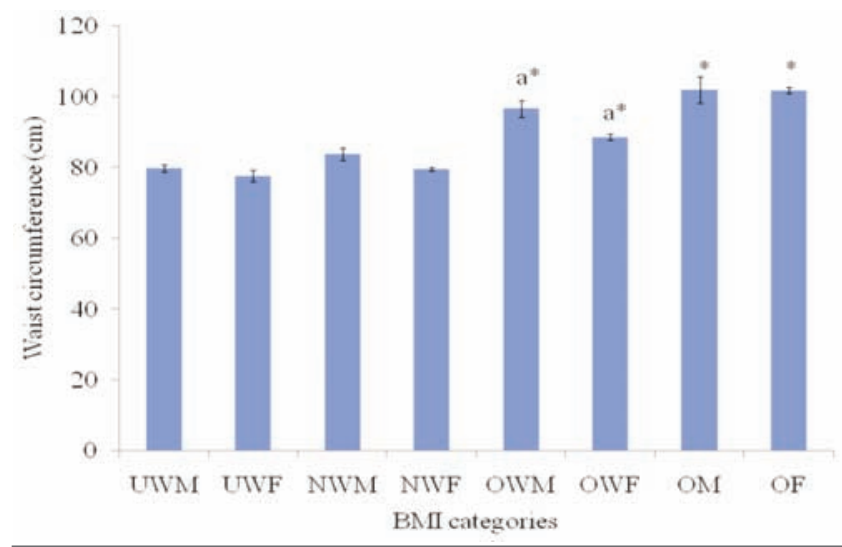

Figure 3. The waist circumference measurement in different BMI distribution categories. Mean value \pm standard error. *Values significantly $(P<0.05)$ different from normal weight. aValues within the same BMI distribution, but significantly $(P<0.05)$ different among gender. UWM = underweight males, UWF = underweight females, NWM $=$ normal weight males, NWF $=$ normal weight females, OWM = overweight males, OWF = overweight females, $\mathrm{OM}=$ obese males, OF represent $=$ obese females.

Table 2. BMI and waist circumference value for early, middle and advanced adulthood.

\begin{tabular}{|c|c|c|c|c|}
\hline Age group & Body weight category & Sex & Mean BMI $\left(\mathrm{kg} / \mathrm{m}^{2}\right)$ & Mean waist circumference $(\mathrm{cm})$ \\
\hline \multirow[t]{8}{*}{ Early adulthood (20-39 years) } & \multirow[t]{2}{*}{ Underweight } & M & $18.03 \pm 0.28 *$ & $78.74 \pm 0.58$ \\
\hline & & $\mathrm{F}$ & $17.15 \pm 0.25^{*}$ & $76.10 \pm 0.53$ \\
\hline & \multirow[t]{2}{*}{ Normal weight } & M & $22.86 \pm 0.43$ & $76.20 \pm 0.58$ \\
\hline & & $\mathrm{F}$ & $21.48 \pm 0.14$ & $78.92 \pm 0.26$ \\
\hline & \multirow{2}{*}{ Overweight } & M & $26.75 \pm 0.43^{*}$ & $88.47 \pm 1.22 *$ \\
\hline & & $\mathrm{F}$ & $26.48 \pm 0.16^{*}$ & $91.08 \pm 0.45^{*}$ \\
\hline & \multirow[t]{2}{*}{ Obese } & M & $39.63 \pm 0.85^{* a}$ & $102.44 \pm 1.45^{*}$ \\
\hline & & $\mathrm{F}$ & $34.34 \pm 0.54^{* a}$ & $100.03 \pm 2.69 *$ \\
\hline \multirow[t]{8}{*}{ Middle adulthood (40-59 years) } & \multirow[t]{2}{*}{ Underweight } & M & $15.39 \pm 0.62 *$ & $79.76 \pm 0.40$ \\
\hline & & $\mathrm{F}$ & $15.50 \pm 0.20^{*}$ & $81.28 \pm 1.15$ \\
\hline & \multirow[t]{2}{*}{ Normal weight } & M & $21.93 \pm 0.37$ & $83.34 \pm 0.90$ \\
\hline & & $\mathrm{F}$ & $21.92 \pm 0.29$ & $81.15 \pm 0.46$ \\
\hline & \multirow[t]{2}{*}{ Overweight } & M & $26.99 \pm 0.26^{*}$ & $98.15 \pm 1.03^{*}$ \\
\hline & & $\mathrm{F}$ & $26.94 \pm 0.32 *$ & $90.86 \pm 0.70^{*}$ \\
\hline & \multirow[t]{2}{*}{ Obese } & M & $31.53 \pm 0.22 * a$ & $96.52 \pm 0.10^{*}$ \\
\hline & & $\mathrm{F}$ & $34.51 \pm 0.80^{* a}$ & $102.34 \pm 0.75^{*}$ \\
\hline \multirow[t]{8}{*}{ Advanced (late) adulthood (60+ years) } & \multirow[t]{2}{*}{ Underweight } & M & $16.60 \pm 0.38 *$ & $79.58 \pm 0.88$ \\
\hline & & $\mathrm{F}$ & $17.58 \pm 0.46^{*}$ & $81.28 \pm 2.01$ \\
\hline & \multirow[t]{2}{*}{ Normal weight } & M & $21.78 \pm 0.96$ & $82.98 \pm 0.88$ \\
\hline & & $\mathrm{F}$ & $21.79 \pm 0.29$ & $81.36 \pm 0.73$ \\
\hline & \multirow[t]{2}{*}{ Overweight } & M & $27.03 \pm 0.84 *$ & $92.28 \pm 0.58 *$ \\
\hline & & $\mathrm{F}$ & $25.83 \pm 0.27^{*}$ & $94.49 \pm 0.62 *$ \\
\hline & \multirow[t]{2}{*}{ Obese } & M & $32.34 \pm 0.63^{*}$ & $104.98 \pm 2.40 *$ \\
\hline & & $\mathrm{F}$ & $32.48 \pm 0.89 *$ & $98.63 \pm 0.44^{*}$ \\
\hline
\end{tabular}

Values are expressed as mean \pm standard error of mean. ${ }^{*}$ Values significantly $(\mathrm{P}<0.05)$ different from normal weight. aValues within the same BMI distribution, but significantly $(\mathrm{P}<0.05)$ different among gender.

Table 3. Correlation table for BMI, waist circumference, weight and height.

\begin{tabular}{|c|c|c|c|c|c|}
\hline & & Waist circumference (in) & Height (m) & BMI $\left(\mathrm{kg} / \mathrm{m}^{2}\right)$ & Body weight (kg) \\
\hline \multirow[t]{2}{*}{ Male } & BMI $\left(\mathrm{kg} / \mathrm{m}^{2}\right)$ & $0.55^{*}$ & $-0.35^{*}$ & 1.00 & $0.77^{*}$ \\
\hline & Body weight (kg) & $0.42^{*}$ & 0.17 & 0.77 & 1.00 \\
\hline \multirow[t]{2}{*}{ Female } & $\operatorname{BMI}\left(\mathrm{kg} / \mathrm{m}^{2}\right)$ & $0.75^{*}$ & -0.17 & 1.00 & $0.85^{*}$ \\
\hline & Body weight (kg) & $0.67^{*}$ & $0.22 *$ & $0.85^{*}$ & 1.00 \\
\hline \multirow[t]{2}{*}{ Total } & BMI $\left(\mathrm{kg} / \mathrm{m}^{2}\right)$ & $0.63^{*}$ & $-0.31^{*}$ & 1.00 & $0.76^{*}$ \\
\hline & Body weight (kg) & $0.62 *$ & $0.23^{*}$ & $0.76^{*}$ & 1.00 \\
\hline
\end{tabular}

*Pearson correlation is significant at the 0.01 level (2-tailed). 
It has been reported that body adiposity index (BAI) is also a good measure of body adiposity in Caucasian population. ${ }^{30}$ However, it does not overcome the reported limitations of BMI. ${ }^{31}$ Waist circumference is a simple measure of abdominal fat and it appears to be a good indicator of adiposity. ${ }^{4,29}$ This study indicates that it is an effective indicator of overweight and obesity but not underweight. BMI on the other hand does not discriminate between fat mass and fat-free mass but can be used to identify body weight abnormalities including underweight.

\section{Conclusions}

In conclusion, the present study demonstrates strong associations between BMI, weight and waist circumference in perceived healthy subjects. Since the waist circumference has been reported as a viable predictor of major metabolic disorder, it is important to assess weight not only on general adiposity but also on abdominal fat, which is highly associated with elevation of health risk. It is also important to sensitise the people in the community on regular weight assessment using BMI and waist circumference parameters. More studies are needed to investigate other body adiposity indices for different age categories in African populations. This will help to establish practical methods for body weight assessment suitable for prediction of morbidity and mortality for both clinical and research purposes.

Correspondence: Olubanke 0. Ogunlana, Department of Biological Sciences, College of Science and Technology, Covenant University, PMB 1023, 112233, Ota, Ogun State, Nigeria. Tel. +234.808 .045 .4316$

E-mail: banke.ogunlana@covenantuniversity.edu.ng

Key words: body mass index, waist circumference, early adulthood, middle adulthood, advanced adulthood.

Acknowledgments: we are grateful to the management and staff of Covenant University, Ado-Odo/Ota Local Government, Covenant University Health Center and Ace Medicare Clinics for providing relevant support and technical assistance for this study. Our appreciation also goes to the traditional heads and chiefs of Iyesi and Ilogbo communities and all the participants. Contributions: the authors contributed equally.

Conflict of interests: the authors declare no potential conflict of interests.

Funding: The study described in the manuscript was funded by Covenant University public Health and Well being research group, Covenant University, Nigeria.

Received for publication: 6 June 2013.

Accepted for publication: 4 September 2013.

CC Copyright S.N. Chinedu et al., 2013

Licensee PAGEPress, Italy

Journal of Public Health Research 2013; 2:e16

doi:10.4081/jphr.2013.e16

This work is licensed under a Creative Commons Attribution NonCommercial

\section{References}

1. World Health Organisation. Physical status: the use and interpretation of anthropometry. 1995. Available from: http://www.who.int/childgrowth/publications/physical_status/en/in dex.html. Accessed on: August 2012.
2. Amuta E, Houmsou RS. Assessment of Nutritional Status of School Children in Makurdi, Benue State. Pakistan J Nutr 2009;8:691-4.

3. Knowler WC, Pettitt DJ, Saad MF, et al. Obesity in the Pima Indians: its magnitude and relationship with diabetes. Am J Clin Nutr 1991;53:S1543-51.

4. Leitzmann MF, Moore SC, Koster A, et al. Waist circumference as compared with body-mass index in predicting mortality from specific causes. PLoS One 2011;6:e18582.

5. Schreiner PJ, Terry JG, Evans GW, et al. Sex-specific associations of magnetic resonance imaging-derived intra-abdominal and subcutaneous fat areas with conventional anthropometric indices. The atherosclerosis risk in communities study. Am $\mathrm{J}$ Epidemiol 1996;144:335-45.

6. Seidell JC, Perusse L, Despres JP, Bouchard C. Waist and hip circumferences have independent and opposite effects on cardiovascular disease risk factors: the Quebec family study. Am J Clin Nutr 2001;74:315-21.

7. Harris TB, Visser M, Everhart J, et al. Waist circumference and sagittal diameter reflect total body fat better than visceral fat in older men and women. The health, aging and body composition study. Ann N Y Acad Sci 2000;904:462-73.

8. Gallagher D, Visser M, Sepulveda D, et al. How useful is body mass index for comparison of body fatness across age, sex, and ethnic groups? Am J Epidemiol 1996;143:228-39.

9. World Health Organization. Obesity: preventing and managing the global epidemic. WHO Consultation on obesity. 2000. Available from: www.who.int/nutrition/publications/obesity/en/index.html. Accessed on: August 2012.

10. Kuczmarski RJ, Flegal KM. Criteria for definition of overweight in transition: background and recommendations for the United States. Am J Clin Nutr 2000;72:1074-81.

11. Olusanya J0, Omotayo OA. Prevalence of obesity among undergraduate students of Tai Solarin University of Education, Ijagun, Ijebu-Ode. Pak J Nutr 2011;10:940-6.

12. Abate N. Obesity as a risk factor for cardiovascular disease. Am J Med 1999;107:12S-13S.

13. Bray GA. Medical consequences of obesity. J Clin Endocrinol Metab 2004;89:2583-9.

14. Boden G. Obesity and diabetes mellitus - how are they linked? West Indian Med J 2002;51:51-4.

15. Bustos P, Amigo H, Oyarzun M, Rona RJ. Is there a causal relation between obesity and asthma? Evidence from Chile. Int J Obes (Lond) 2005;29:804-9.

16. Wadden TA, Brownell KD, Foster GD. Obesity: responding to the global epidemic. J Consult Clin Psychol 2002;70:510-25.

17. Flegal KM, Graubard BI, Williamson DF, Gail MH. Excess deaths associated with underweight, overweight and obesity. JAMA 2005;293:1861-7.

18. Odenigbo UM, Odenigbo CU, Oguejiofor OC. Nutritional status of elderly in Asaba, Delta State, Nigeria. Pak J Nutr 2010;9:416-8.

19. Yahia N, Achkar A, Abdallah A, Rizk S. Eating habits and obesity among Lebanese university students. Nutr J 2008;7:32.

20. Arroyo Izaga M, Rocandio Pablo AM, Ansotegui Alday L, et al. Diet quality, overweight and obesity in universities students. Nutr Hosp 2006;21:673-9.

21. Bertsias G, Mammas I, Linardakis M, Kafatos A. Overweight and obesity in relation to cardiovascular disease risk factors among medical students in Crete, Greece. BMC Public Health 2003;3:3.

22. Al-Isa AN. Obesity among Kuwait University Students: an explorative study. J R Soc Promot Health 1999;119:22327.

23. Galore SR, Walker C, Chandler A. Brief communication: dietary habits of first-year medical students as determined by computer software analysis of three-day food records. J Am Coll Nutr 1993;12:517-20. 
24. Gortmaker SL, Must A, Perrin JM, et al. Social and economic consequences of overweight in adolescence and young adulthood. $\mathrm{N}$ Engl J Med 1993;329:1008-12.

25. Houston DK, Ding J, Nicklas BJ, et al. Overweight and obesity over the adult life course and incident mobility limitation in older adults: the health, aging and body composition study. Am J Epidemiol 2009;169:927-36.

26. Courtemanche $\mathrm{C}$. Longer hours and larger waistlines? The relationship between work hours and obesity. Forum for health Economics and Policy 2009;12:21.

27. Vazquez G, Duval S, Jacobs DR, Silventoinen K. Comparison of body mass index, waist circumference, and waist/hip ratio in predicting incident diabetes: a meta-analysis. Epidemiol Rev
2007;29:115-28.

28. Ford ES, Mokdad AH, Giles WH. Trends in waist circumference among U.S. adults. Obes Res 2003;11:1223-31.

29. Cameron AJ, Welborn TA, Zimmet PZ, et al. Overweight and obesity in Australia: the 1999-2000 Australian diabetes, obesity and lifestyle study (AusDiab). MJA 2003;178:427-32.

30. Bergma RN, Stefanovski D, Thomas A, et al. A better index of body adiposity. Obesity 2011;19:1083-9.

31. Bennasar-Veny M, Lopez-Gonzalez AA, Tauler P, et al. Body adiposity index and cardiovascular health risk factors in caucasians: a comparison with the body mass index and others. PLoS One 2013;8:e63999. 